DOI: $10.33876 / 2311-0546 / 2020-52-4 / 188-198$

(С) Б.А. Синанов, Л.Т. Соловьева

\title{
ГРУЗИНСКАЯ ДИАСПОРА НА СЕВЕРНОМ КАВКАЗЕ: НЕКОТОРЫЕ АСПЕКТЫ ДУХОВНОЙ КУЛЬТУРЫ*
}

В жизни грузинской диаспоры Северной Осетии в последние годы важным событием стал праздник Ломисоба. Он проводится в первую среду после дня Святой Трочџы в окрестностях селения Балта, расположенного на Военно-грузинской дороге. Истоки этого праздника уходят в грузинский регион Мтиулети, где местные жители почитают св. Георгия Ломисского, именной праздник которого - Ломисоба - ежегодно проводится в селении Млета. Грузины Балты, как и жители соседних селений Чми и Нижний Ларс, сохраняют в быту немало народных традиций из сферы духовной культуры (народные верования, семейная и календарная обрядность); отчасти этому способствует сохранение постоянных контактов с сородичами из соседних районов Грузии. Праздники в большинстве полиэтничных регионов Кавказа, как правило, всегда создавали благоприятные условия для общения представителей не только разных народов, но и разных конфессий. Как свидетельствуют собранные материаль, эта особенность праздничной культуры сохраняется и в наши дни.

Ключевые слова: грузинская диаспора, Северный Кавказ, Северная Осетия, духовная культура, праздник Ломисоба, межэтнические отношения

На сегодняшний день одна из наиболее значительных и старейших грузинских диаспор на территории Российской Федерации сосредоточена в Республике Северная Осетия - Алания (РСО-А). По данным Всероссийской переписи населения 2010 г. в республике проживает 9095 этнических грузин. Среди регионов Российской Федерации это третья по численности грузинская диаспора, больше только в Москве (38 934 чел.) и в Краснодарском крае (17 826 чел.), всего грузин в России 157803 чел. (Социально-демографический 2012: 87, 94, 95, 96).

Начало формирования грузинской диаспоры в пределах Северного Кавказа традиционно связывается с Персидским походом Петра I в 1722-1723 гг. и присоединением на непродолжительное время части прикаспийских территорий, находившихся во

Синанов Борис Андреевич - к.и.н., старший научный сотрудник, Северо-Осетинский институт гуманитарных и социальных исследований им. В.И. Абаева Владикавказского научного центра Российской академии наук (Владикавказ, пр. Мира, 10). Эл. почта: boris-sinanov@yandex.ru.

Соловьева Любовь Тимофеевна - к.и.н., старший научный сотрудник, Институт этнологии и антропологии РАН (Москва, Ленинский пр., 32А). Эл. почта: lubsolov@gmail.com.

* Публикуется в соответствии с планом научно-исследовательских работ Института этнологии и антропологии РАН 
владении Ирана. В течение всего XVIII в. на российских территориях Северного Кавказа грузинские поселения сосредотачивались в двух районах - в Прикаспии и в Притеречье. В Прикаспии основными центрами поселенцев-грузин были крепость Святого Креста и Дербент. В свою очередь в Притеречье местом локализации переселенцев из Грузии выступали Кизляр и Моздок, а также небольшие поселения на левом берегу Терека, позже преобразованные в станицы, такие как Шелковская (Сарафанниково), Новогладковская и Сасоплинская. И если в прикаспийских территориях грузинские общины просуществовали лишь до 1735 г., то общины грузин Притеречья оказались более устойчивыми и продолжили свою историю вплоть до ХХ в., частично ассимилировавшись с местным населением, в том числе через переход в казачье сословие, частично, мигрировав в другие регионы России. Немногочисленные потомки

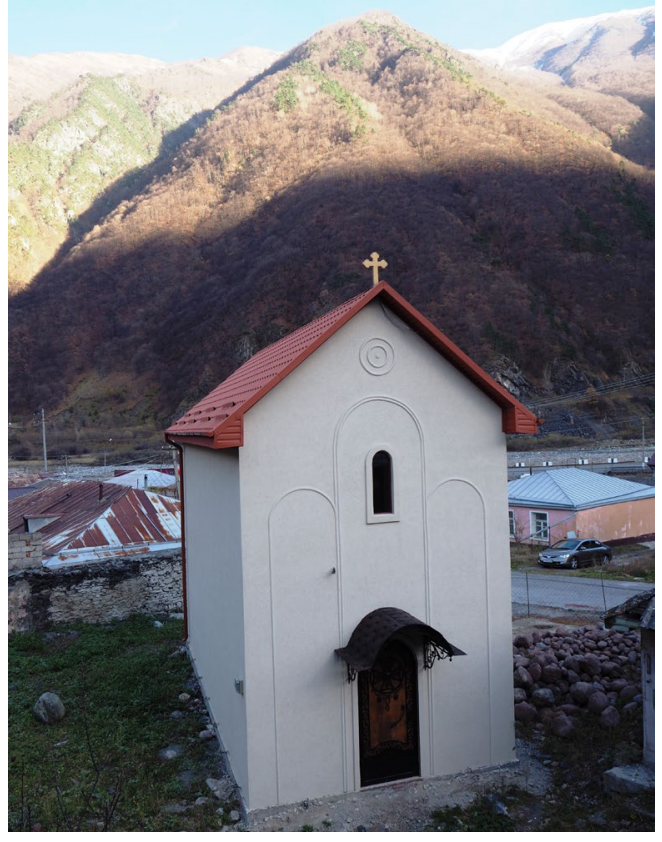

Рис. 1. Возобновленный храм святителя Николая Чудотвориа. Селение Нижний Ларс. Фото 2018 г. первопоселенцев Притеречья проживают до наших дней в городах Моздок и Кизляр.

Исследователи выделяют две основные предпосылки возникновения и существования компактных грузинских поселений на Северном Кавказе. Первой причиной было бедственное состояние Грузии. За предшествующие несколько веков усиленно шел процесс разрушения грузинского этнического массива. Ко второй половине XVIII в. процесс рассеяния грузинского этноса достиг катастрофической степени. Набеги на территорию Восточной Грузии, организуемые со стороны Дагестана, имели следствием захват пленных с целью получения выкупа или использования их в качестве рабов. «Уведенные насильственно на северный склон Большого Кавказа малыми группами жители Грузии спасались от плена и рабства бегством в российские пределы. Конечно, это удавалось лишь малой части пленных» (Гамрекели 1968: 93).

К другим формам этнической миграции относят добровольные переселения, изгнания, бегство от гнета или от кары. Социально-экономические условия Грузии в течение всего XVIII в. давали немало поводов для подобного перемещения жителей Грузии на Северный Кавказ. Вследствие этого, оказавшись в сложной ситуации у себя на родной земле, либо в неволе на северном склоне Кавказа, часть представителей грузинского этноса была заинтересована в обретении свободы и новой родины.

Второй предпосылкой возникновения грузинских поселений была экспансия России на Кавказ. Расширяя свои границы на юге, государство было заинтересовано в благонадежном населении, которое и было представлено в лице исповедующих христианство грузин и армян.

Общая численность грузин Притеречья в последней четверти XVIII в. насчитывала 2,5-3 тыс. чел. На протяжении второй половины XVIII столетия грузинская община Кизляра составляла от 25 до 15\% гражданского населения, и от 53 до 20\% 
гражданского населения Моздока. И хотя в абсолютных выражениях численность грузин Притеречья была невелика (от 470 чел. в 1775 г., до 805 чел в 1798 г. - в Кизляре, и от 120 чел. в 1764 г. до 933 чел. в 1789 г. - в Моздоке), исследователи подчеркивают значимость их во взаимоотношениях Грузии, России и Северного Кавказа (Гамрекели 1968: 51-52, 95).

В дальнейшем, с расширением территорий Российской империи в направлении Центрального Кавказа, новые грузинские поселения стали возникать и в центре региона, крепостях - Владикавказ, Грозный, Нальчик и слободе Алагир. Наблюдается следование грузинских поселений за изменением российских границ, за расположением российских гарнизонов на Северном Кавказе.

В XIX в. экономические причины вынуждают часть представителей различных этнокультурных общностей грузин (рачинцы, мохевцы, мтиулы и др.) к переселению на расположенные по соседству северные склоны Центрального Кавказа. В 18701880-е годы началось активное переселение грузин в Алагир. Первым грузиномпоселенцем считали Шио Джапаридзе, происходившего из селения Они Рачинского уезда Кутаисской губернии. С 1879 до середины 1880-х годов в Алагир переселились около 200 семей рачинцев (по другим данным - 120) (Канукова, Федосова 2011: 134). Имеретины из Рачинского уезда переселялись в Алагирское ущелье в надежде на спасение от нищеты и голода, поразивших население в связи с неурожаями, случавшимися на протяжении нескольких лет (Цориева 2011: 165).

Острая нехватка плодородной земли горной Грузии стала причиной раннего отходничества и развития ремесел. Рачинцы были известны как столяры, пильщики, каменщики, хлебопеки. Для жителей Верхней Рачи самой удобной для переселения на Северный Кавказ в Россию была Военно-Осетинская дорога, проходившая через Мамисонский перевал. Строительство Алагирского серебро-свинцового завода и нового поселения привлекло рачинцев - столяров, плотников, пильщиков, специалистов по обжигу извести.

Рачинцы старались открыть в Алагире грузинскую школу, но долгое время не находили поддержки властей. В 1899 г. им было разрешено основать церковно-приходскую школу. Она была устроена в доме Алексея Лобжанидзе. Лишь в ноябре 1911 г. состоялось торжественное открытие нового здания грузинской школы. Школа была построена на участке Д.Л. Метревели в 1907-1908 гг. на добровольные пожертвования, собранные в разных уголках Кавказа.

По данным на январь 1899 г. в Алагире проживали 736 грузин. Большинство из них занимались ремеслами, строительными работами. Дома многих русских и осетин были возведены руками рачинских строителей. Грузины приобретали земли у местного населения, у завода и обзаводились хозяйством. Благодаря трудолюбию и умению приноровиться к новым условиям жизни они значительно улучшили свое материальное положение. Некоторые из них с годами становились настолько состоятельными, что могли позволить себе отправлять детей учиться в учебные заведения Тифлиса и Кутаиси. Многие грузинские священнослужители, к примеру, Габриел Бочоришвили, Филипп Унгиадзе, И. Елиосидзе, Ш. Двашвили, несли церковную службу в Алагирском соборе и работали учителями в церковноприходской школе (Цориева 2011: 165). Рачинцы находились в Алагире в статусе «временнопоселенных». По некоторым данным, в Алагире проживало 400 осетинских семей, 300 грузинских и около 200 русских (Канукова, Федосова 2011: 135). 
Во Владикавказе грузины живут на протяжении всей его истории. В бытность крепостью владикавказских грузин вместе с армянами насчитывалось 99 человек (Канукова, Федосова 2011: 140), но с преобразованием в город численность грузин заметно выросла, хотя и была подвержена колебанию. Из отчета начальника Терской области и Наказного атамана Терского казачьего войска за 1910 г. следует, что в 1894 г. в городе насчитывалось 950 грузин, в 1897 г. - 1612, в 1903 г. - 830, а в 1910 г. - 3070 (Многонациональные... 2012: 258).

Грузинское население Владикавказа формировалось в ходе одиночных или групповых, немногочисленных миграций (Канукова, Федосова 2011: 140). Современники указывали на существование в городе «мохевской» части, где компактно проживали грузины-мохевцы (переселенцы из области Хеви). Они появились во Владикавказе в начале XX в. Крупные торговцы, выходцы из Грузии, предприниматели, владельцы гостиниц жили в центре города, а основная масса грузинских переселенцев обосновалась во Владимирской, Молоканской слободках и на Шалдоне.

Грузины из Душетского уезда в начале 1890-х годов поселялись в Осетинской слободке, где самовольно возводили постройки. К началу XX в. увеличилась численность городского населения вообще и грузинского в частности, особенно в затеречной части города. В 1911 г. настоятель Константино-Еленинской церкви указывал, что там проживало 1373 грузина.

Экономическая основа грузинской общины была достаточно крепкой, что позволило ей создавать диаспорную структуру.

В ноябре 1888 г. во Владикавказе состоялось торжественное открытие грузинской школы. Ее основали по инициативе грузинского просветителя и общественного деятеля Михаила Зааловича Кипиани (1833-1891), при активном участии грузинской общины города. Занимая с 1871 г. пост управляющего межевой частью Терской области, Кипиани принимал активное участие в передовых начинаниях владикавказской интеллигенции. Он также был одним из инициаторов создания «Общества распространения образования и технических сведений среди горцев Терской области», впервые перевел на грузинский язык труды В.Г. Белинского, активно сотрудничал в кавказских газетах. Михаил Кипиани хорошо знал одного из основоположников осетинского литературного языка Коста Хетагурова и дружил с ним (Киреев 2015: 13-14). В начале 2000-х годов на фасаде школы была установлена мемориальная доска в память о дружбе Коста Хетагурова и Михаила Кипиани.

Первое время грузинская школа располагалась в арендованном помещении, но затем для нее построили специальное здание. Просторный актовый зал использовался для проведения различных мероприятий не только грузинами, но и осетинами, армянами и другими этническими общинами.

При грузинской школе 1 ноября 1898 г. епископом Владикавказским и Моздокским Владимиром (Сеньковским) был освящен храм святой равноапостольной Нины, просветительницы Грузии. Распоряжением Святейшего Синода храм был объявлен приходским «с причтом из священника и псаломщика» (Терские ведомости 1898). Помимо городского населения к приходу храма был причислен хутор Камбилеевский, а общая численность прихожан - этнических грузин - на начало века составляла 2068 человек (Беляев 2008: 308). Первыми клириками храма стали священник Георгий Григорьевич Натадзе и диакон Георгий Александрович Таблиев. 
После революции 1917 г. самая ранняя попытка закрыть церковь была предпринята в августе 1928 г. Городской совет постановил изъять у грузинской общины помещение церкви святой Нины, а чуть позже потребовал очистить здание храма от церковной утвари. Православная грузинская община попыталась обжаловать это решение, но безрезультатно. Ответ был однозначным: церковь закрыть. Однако реальных шагов со стороны власти не последовало, и храм продолжал действовать еще пять лет. Только в октябре 1933 г. здание церкви было передано под библиотеку артиллерийского полка, а с 1935 г. стало использоваться как одно из помещений грузинской школы. В 1933 г., накануне закрытия, в этом храме был крещен уроженец Владикавказа будущий Католикос-Патриарх всея Грузии Илия II. В октябрь 1997 г. в ходе своего визита во Владикавказ Патриарх Илия II посетил грузинскую школу и помещение бывшей церкви. Средняя общеобразовательная грузинская школа № 19 функционирует и сегодня.

13 марта 2011 г. в Неделю Торжества Православия, при собрании большого количества молящихся, в храме было совершено первое с момента закрытия богослужение. Праздничный молебен совершил благочинный церквей Владикавказского округа протоиерей Василий Шауэрман в сослужении священника храма Покрова Пресвятой Богородицы иерея Георгия Болотаева, который в 2013 г. был назначен ответственным за восстановление храма. С этого года, несмотря на аварийное состояние, молебны в храме совершаются регулярно. Богослужения проходят на церковнославянском, грузинском и осетинском языках. 27 января 2016 г. в возрождаемом храме равноапостольной Нины состоялась первая в новейшей истории храма Божественная литургия. Богослужение совершил протоиерей Константин Джиоев, получивший образование в Мцхетской духовной семинарии, в совершенстве владеющий грузинским языком и имеющий опыт служения на грузинским языке. Помимо богослужений, силами прихода в храме с 2015 г. проводятся рождественские праздники, интерьер церкви пополняется преподносимыми в дар новыми иконами, а в 2016 г. был возведен временный иконостас.

Возрождение церковной жизни происходит и в приграничном с Грузией селении Нижний Ларс (официально входит в состав городского округа города Владикавказа). Село является первым российским населенным пунктом на границе с Грузией и расположено в 6 километрах от нее. В Нижнем Ларсе проживает около 150 человек (40 домов), в подавляющем большинстве это этнические грузины-мохевцы.

Первый православный храм в честь Святителя Николая Чудотворца был построен в селении в 1839 г. В 1895 г. его перестроили и вновь освятили. К этому времени его прихожанами являлись жители не только Нижнего Ларса, но и окрестных сел - Чми и Балта. Под сводами храма вместе молились грузины, осетины, русские (начало XX в. - около 400 человек). В годы советской власти храм был закрыт и со временем пришел в запустение. К 2010 г. остались только стены, местами покрытые глубокими трещинами. В 2011 г. с благословения Владикавказской епархии местными энтузиастами было принято решение о возведении нового храма на месте старого, в основу которого были положены камни то разобранной старой церкви.

В сентябре 2017 г. архиепископ Владикавказский и Аланский Леонид посетил строящийся храм в Нижнем Ларсе, и обсудил с его настоятелем священником Георгием Болотаевым и представителями местной православной общины вопросы жизнедеятельности прихода. 19 декабря 2019 г., в день памяти святого Николая Чудотворца, в одноименном храме прошли престольные торжества. На первую литургию 
в храме Святителя Николая Чудотворца собрались десятки православных верующих - местных жителей, а также паломников из Владикавказа и ближайших сел.

На сегодняшний день основные строительные работы практически завершены. Продолжается обустройство прилегающей территории и оформление внутреннего убранства храма.

Согласно данным последней переписи 2010 г., грузинское население Республики Северная Осетия-Алания составляет 9095 чел., или 1,3\% общей численности населения (Социально-демографический 2012: 96). Грузины являются шестым по численности этносом в республике. Основное грузинское население проживает во Владикавказе, а также в населенных пунктах, расположенных у границы с Грузией по Военно-грузинской дороге: Балта, Чми и Нижний Ларс. На сегодняшний день организационно 600 представителей грузинского этноса являются членами грузинского национально-культурного общества «Единство» - «Эртоба», зарегистрированного в республике с 1 апреля 1990 г. (Сайт газеты «Северная Осетия») и около 30 человек объединены в общество «Иверия» Моздокского района.

Таблица 1

Динамика этнического состав населения Северной Осетии 1989-2010 гг. (по официальным данным Переписей населения 1989, 2002 и 2010 гг.)

\begin{tabular}{|c|c|c|c|c|c|c|}
\hline \multirow{3}{*}{ Этносы } & \multicolumn{6}{|c|}{ Переписи } \\
\hline & \multicolumn{2}{|c|}{1989} & \multicolumn{2}{|c|}{2002} & \multicolumn{2}{|c|}{2010} \\
\hline & человек & $\begin{array}{c}\text { в \% } \\
\text { к итогу }\end{array}$ & человек & $\begin{array}{c}\text { в \% } \\
\text { к итогу }\end{array}$ & человек & $\begin{array}{c}\text { в \% } \\
\text { к итогу }\end{array}$ \\
\hline Все население & 632428 & 100,0 & 710275 & 100,0 & $706423^{1}$ & 100,0 \\
\hline Осетины & 334876 & 52,9 & 445310 & 62,7 & 459688 & 65,1 \\
\hline Русские & 189159 & 29,9 & 164734 & 23,2 & 147090 & 20,8 \\
\hline Ингуши & 32783 & 5,2 & 21442 & 3,0 & 28336 & 4,0 \\
\hline Армяне & 13619 & 2,1 & 17147 & 2,4 & 16235 & 2,3 \\
\hline Кумыки & 9478 & 1,5 & 12659 & 1,8 & 16092 & 2,3 \\
\hline Грузины & 12284 & 1,9 & 10803 & 1,5 & 9095 & 1,3 \\
\hline
\end{tabular}

Как видно из приведенной таблицы, незначительное снижение численности грузинского населения в период с 1989 по 2010 гг., чаще всего, не связывается с грузино-югоосетинскими конфликтами начала 1990-х годов и августа 2008 г. Указанные события, в некоторых случаях, действительно, могли стать поводом для того чтобы покинуть пределы Северной Осетии (главным образом, в начале 1990-х годов), но все же, не привели к массовому исходу грузин из республики. Интеграция грузинского населения Северной Осетии, в первую очередь, потомков одних из первых поселенцев Владикавказа и Моздока, с одной стороны, и взаимопроникновение культур, родственные связи, православная вера и знание грузинского языка большей частью югоосетин-

\footnotetext{
${ }^{1}$ Указавшие свою национальность. Все население - 712980 чел.
} 


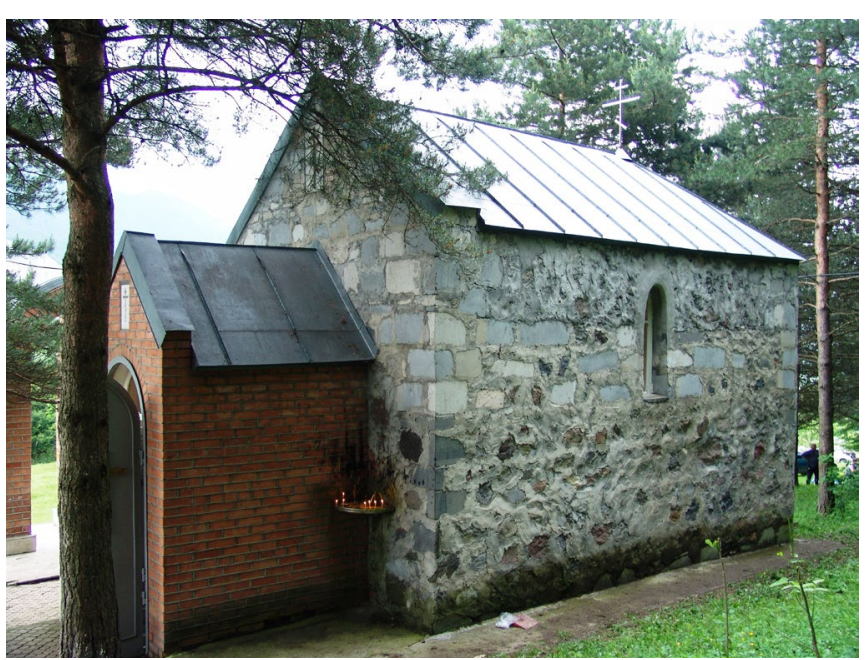

Рис. 2. Селение Балта. Часовня св. Георгия Победоносиа.

ских переселенцев - с другой, свели к минимуму возможность возникновения межэтнических противоречий.

Как показывают полевые материалы, представители грузинской диаспоры, проживающие на Северном Кавказе, сохраняют в быту немало традиционных элементов из сферы духовной культуры (народные верования, семейная и календарная обрядность и т.д.). В жизни представителей грузинской диаспоры Северной Осетии и соседних регионов в последние годы важным событием стал праздник Ломисоба. Он проводится в первую среду после дня Святой Троицы в окрестностях с. Балта. Истоки этого праздника уходят в грузинский регион Мтиулети, где местные жители почитают св. Георгия Ломисского, именной праздник которого - Ломисоба - ежегодно проводится в мтиульском селении Млета.

Как отмечает в своем исследовании В.В. Бардавелидзе, Ломисас хати, расположенное $в$ селении Млета, было важным региональным святилищем. По народным представлениям, оно считалось общим покровителем двух горных регионов Восточной Грузии - Мтиулети и Гудамакари, поэтому наибольшим почитанием оно пользовалось именно у мтиулов и гудамакарцев (Бардавелидзе 2015: 22).

Ломисас хати, по народным представлениям, считалось очень «сильным», могущественным, поэтому оно почиталось и в соседних горных регионах Восточной Грузии. Ломисский св. Георгий упоминается не только в мтиульских священнослужебных текстах, но также в пшавских и мохевских. В народе верят, что Ломисский св. Георгий способен помочь бездетным, тяжелобольным, сюда приходят молиться о выздоровлении, о даровании детей, об исцелении от слепоты и других недугов, о благополучии семьи. Живущие в Северной Осетии грузины традиционно посещали этот праздник.

По рассказам местных жителей, в 1950-е годы один из жителей с. Балта, Симон Павлиашвили, перенес несколько камней из святыни в Млета в окрестности своего села, где им было сооружено святилище в честь св. Георгия Ломисского. Симона Павлиашвили в народе почитали как ясновидящего и называли «мона». Предки Симона Павлиашвили происходили, судя по рассказам его потомков, из селения Павлиани Ахалгорского района. В селении Павлиани тоже было святилище Ломисского св. Георгия, и деканозов там выбирали именно из фамилии Павлиашвили. Он же, следуя указаниям высших сил, начал возводить святилища Эртабрдзанеблоба и Мариамоба. Из Грузии он принес и металлический крест.

Это произошло в 1950-е годы, когда власти не только закрывали христианские храмы, но и боролись с местными святынями. Судя по рассказам местных жителей, Симон Павлиашвили также пострадал от властей и даже провел несколько 
лет в заключении из-за того, что он возвел святое место - традиционную для горных регионов Восточной Грузии каменную постройку с нишей для возжигания свечей и с каменным крестом наверху.

Почему же в селении Балта появился как бы «филиал» так глубоко почитаемого в Грузии святилища? Подобная практика, как отмечают исследователи, была повсеместно распространена среди грузин-горцев. Одной из главных причин этого, как правило, были миграции.

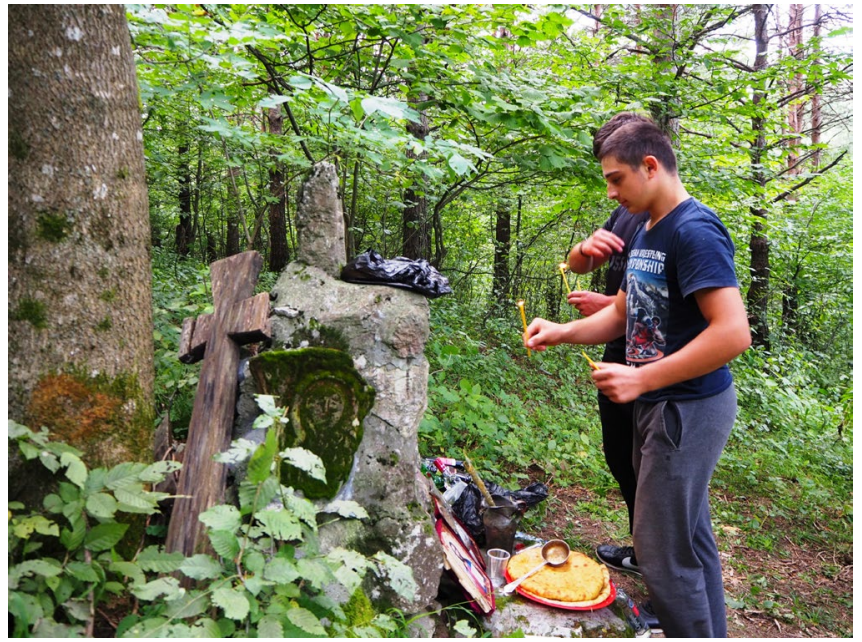

Рис. 3. Селение Балта. Праздник Мариамоба, 28 августа. Фото 2019 г.

Как отмечает В.В. Бардавелидзе, «по древнему обычаю грузины во время переселений брали с собой какую-нибудь реликвию своего святилища - горсть земли, небольшой обломок с ниши, либо камушек, священную чашу или что-либо другое и помещали его на культовую “башню”, которую выстраивали во имя своего исконного покровителя на новом месте жительства». Например, переселение хевсур и пшавов в Тушети было «одним из путей внедрения культа их божеств» в этом регионе (Бардавелидзе 2015: 26).

Следует отметить, что грузины, предки которых переселились в Северную Осетию из Мтиулети (жители с. Балта) и Хеви (жители с. Нижний Ларс, Чми), никогда не забывали своих главных святилищ (Ломиси для мтиулов и Самеба/Самебис хати для мохевцев), периодически совершая туда паломничества. Это могло быть связано с тем или иным обетом; во время ежегодных праздников в этих храмах обычно крестили детей. Так, Элгуджа Павлиашвили (деканоз) вспоминает, как его отец Симон ходил на моление в свое родовое святилище Ломисского св. Георгия в с. Павлиани и вел туда на заклание трехлетнего бычка. Причем он отметил интересную деталь: по его словам, скотина, которую ведут на заклание, обычно идет спокойно, не сопротивляясь. Его отец часть пути шел пешком, и бычок «охотно» шел за ним, не доставляя никаких хлопот. И в настоящее время местные жители-грузины сохраняют глубокую веру в силу и могущество Ломисского св. Георгия и Гергетской Троицы - Самебис хати.

Святилище Ломиси, возведенное около с. Балта, также глубоко почиталось местным христианским населением. Здесь полагалось соблюдать определенные правила: например, с территории вокруг святилища нельзя было ничего брать; из мяса принесенных в жертву животных нельзя было жарить шашлыки - его обязательно варили, сюда не полагалось приносить водку или араку, только вино или пиво. В народе известно немало случаев, когда нарушение правил, неподобающее поведение в святилище и поблизости от него приводили к неприятным событиям, которые воспринимались как наказание за совершенный проступок. По народным представлениям, нельзя было нарушать обет, который давали в том или ином случае. По местной традиции, когда по обету приносили в жертву барашка, то полагалось делать это три 
года подряд. Сохраняется и традиционный ритуал - приношение в жертву баранов (белого или «красного»), пива или вина, пирогов «гулиани када», возжигание восковых свечей. В отличие от Ломисоба в Млета, здесь не принято приношение в жертву кур в виде «гапрена» (груз. «гапрена» - «улететь», «полет», т.е. кур выпускали возле храма или святого места, позволяли им «улететь»).

В 1998 г. около с. Балта, рядом со святилищем, были возведены часовня во имя св. Георгия Победоносца и кладовая для хранения припасов и инвентаря. Ежегодно обустраивается окружающая территория. В часовне в дни праздников священники проводят богослужения, совершают таинство Крещения. Около святого места избранные народом деканозы благословляют принесенные пожертвования.

Праздник Ломисоба в с. Балта в последние годы становится особенно многолюдным, его посещают в основном христиане - не только грузины, но и осетины, армяне, русские. Он стал важным явлением и в общественной жизни республики, которое находит широкое отражение в СМИ и социальных сетях. Любопытно, что хотя число посещающих Ломисоба и приносящих в жертву животных (барашков) весьма значительно, здесь нет выступлений против этого. В Грузии же уже несколько лет развивается движение за запрещение жертвоприношений животных, составляются петиции, где эти традиции объявляют жестокими и осуждаются как отсталые.

Праздники в большинстве полиэтничных регионов Кавказа, как правило, всегда создавали благоприятные условия для общения представителей не только разных народов, но и разных конфессий. Как свидетельствуют собранные материалы, эта особенность праздничной культуры сохраняется и в наши дни.

Отметим еще один момент. Конечно, появление государственной границы осложнило проведение традиционного паломничества грузин Северной Осетии к своим региональным и родовым святыням, которые находятся сравнительно недалеко - в соседних регионах Грузии - Хеви (Гергетская Самеба), Мтиулети (Ломисский св. Георгий) и многие другие. Тем не менее, появление «филиала» святилища Ломиси в селении Балта относится еще к 1950-м годам, когда подобной границы еще не было.

Помимо широко известного святилища Ломисского св. Георгия, в окрестностях Балты есть еще несколько святилищ: Эртабрдзанелоба (туда идут молиться на 2-й день после Ломисоба (там проводят ночное моление - «гамистева»). Из принесенного на Ломисоба мяса берут 7 бараньих лопаток, варят около Эртабрдзанелоба. Несут туда также свечи и гулиани када, как и на Ломисоба, - пирог с начинкой (муку пережаривают на топленом масле и добавляют сыр). Имеются и другие святилища: например, Мариоба (здесь молятся в день Успения Богородицы) и др.

Большинство фамилий грузин с. Балта (Бутхузи, Карелидзе, Миделашвили, Павлиашвили, Тиникашвили, Элошвили, Циптаури) происходит из Ксанского ущелья (Ахалгори), где у них имеются свои родовые святилища. Обосновавшиеся в окрестностях селения Балта представители этих фамилий также возвели «филиалы» своих родовых святилищ (Гандзи, Кашветоба, Цихисмтавармоцме, Тиникаант сахмто, Груисис цминда Гиорги и др.).

Видимо, в строительстве «филиалов» родовых святилищ можно видеть и стремление сакрально «освоить» территорию в окрестностях села, и желание грузин-переселенцев «приблизить» свое главное родовое святилище к месту их нового обитания, поскольку Ломисский св. Георгий воспринимается как покровитель всей общины, а родовые святилища - как покровители определенных семейных коллек- 
тивов. Таким образом, ландшафт в окрестностях с. Балта постепенно был сакрально «освоен» грузинами-переселенцами, причем если день Ломисоба в последнее время стал практически общереспубликанским праздником, то дни молений в других святилищах остаются событиями, которые представляются важными только для жителей данного поселения. Аналогичная ситуация наблюдается и в других грузинских селениях Северной Осетии. Так, в с. Нижний Ларс имеются святилища, где устраиваются праздники Иваноба, Гиоргоба, Атенгеноба.

Следует отметить, что сохранение многих элементов этнической культуры (в первую очередь семейная обрядность, праздничная культура) характерно не только для сельчан, но и для представителей грузинской диаспоры, живущих в городах. В значительной степени это связано с тем, что грузинская диаспора прочно сохраняет свою этническую идентичность; способствует этому также наличие постоянных контактов грузинского населения Северной Осетии с сородичами из соседних регионов Грузии.

\section{Источники и материалы}

Гамрекели 1968 - Гамрекели В.Н. Документы по взаимоотношениям Грузии с Северным Кавказом в XVIII в. Тбилиси, 1968. 335 с.

Многонациональные 2012 - Многонациональные и поликонфессиональные традиции Осетии. Исторический ракурс. Сборник документов / сост. Н. Чиплакова, Л. Засеева, Л. Ленник. Владикавказ, 2012. 332 с.

Сайт газеты «Северная Осетия» - Сайт газеты Северная Осетия. Перевыборы в «Эртобе» http://sevosetia.ru/Article/Index/231220.

Социально-демографический 2012 - Социально-демографический портрет России: По итогам Всероссийской переписи населения 2010 года / Федер. служба гос. статистики. М.: ИИЦ «Статистика России», 2012. 183 с.

Терские ведомости 1898 - Терские ведомости. 1898. № 144. 6 декабря.

\section{Научная литература}

Бардавелидзе В.В. Древнейшие религиозные верования и обрядовое графическое искусство грузинских племен. М.: Наука - Восточная литература, 2015. 445 с.: ил. - (Этнографическая библиотека / редколл.: В.А. Тишков (пред.) и др.).

Беляев Иоанн, протоиерей. Русские миссии на окраинах. Историко-этнографический очерк. (Исторический очерк распространения и восстановления христианства среди осетин). Преосвященный Иосиф, епископ Владикавказский (1821-1890). Историкобиографический очерк жизни и деятельности «апостола Осетии» и первого архипастыря Владикавказской епархии (Составил священник Иоанн Попов) / Сост., ред. А.А. Горобец. Владикавказ: Олимп, 2008. 416 с., ил. 16, карта - (Кавказ христианский).

Канукова 3.В., Федосова Е.В. Этнокультурное пространство Северной Осетии. Владикавказ: ИПО СОИГСИ, 2011. $296 \mathrm{c.}$

Киреев Ф.С. Из истории храма святой равноапостольной Нины // Чырыстон Ир (Православная Осетия). 2015. № 1 (4). С. 13-15.

Цориева И.Т. Пути исповедимые... Из истории основания равнинных поселений на Кавказе в конце XVIII - XIX в. Владикавказ: ИПО СОИГСИ, 2011. 253 с. 
Sinanov, Boris A., Solovyeva, Lyubov T. *

\title{
The Georgian Diaspora in the North Caucasus: Some Aspects of Spiritual Culture
}

\author{
DOI: $10.33876 / 2311-0546 / 2020-52-4 / 188-198$
}

In recent years, the Lomisoba holiday has become an important event in life of the Georgian diaspora in North Ossetia. It is held on the first Wednesday after the Holy Trinity (Troitsa) in the vicinity of the village Balta, located on the Georgian Military Highway. The origins of this holiday go to the Georgian region of Mtiuleti, where locals venerate St. George of Lomisy, whose personal holiday - Lomisoba - is held annually in the village Mleta. The Georgians of Balta, as well as the inhabitants of the neighboring villages Chmi and Nizhny Lars, maintain many folk traditions from the sphere of spiritual culture (folk beliefs, family and calendar rituals). This is partly due to the maintenance of constant contacts with relatives from neighboring regions of Georgia. As a rule, holidays in most of the multi-ethnic regions of the Caucasus have always created favorable conditions for communication between representatives not only of different peoples, but also of different confessions. According to the collected materials, this is still the case for the festive culture.

Key words: the Georgian diaspora, North Caucasus, North Ossetia, spiritual culture, the Lomisoba holiday, interethnic relations

* Sinanov, Boris A. - PhD in hist., V. I. Abaev North Ossetian Institute for Humanitarian and Social Studies of the Vladikavkaz Scientific Centre of RAS (Vladikavkaz, Russia). E-mail: boris-sinanov@yandex.ru

Solovyeva, Lyubov T. - PhD in hist., Senior researcher, Institute of Ethnology and Anthropology, RAS (Moscow, Russia).E-mail: lubsolov@gmail.com

The research is published as part of the Research Plan of the Institute of Ethnology and Anthropology (Russian Academy of Sciences, Moscow)

\section{References}

Bardavelidze, V.V. 2015. Drevneishie religioznye verovaniia i obriadovoe graficheskoe iskusstvo gruzinskikh plemen [The oldest religious beliefs and ceremonial graphic art of the Georgian tribes], edited by V.A. Tishkov. Moscow: Nauka - Vostochnaia literatura, (Etnograficheskaia biblioteka).

Beliaev Ioann, protoierei. 2008. Russkie missii na okrainakh. Istoriko-etnograficheskii ocherk. (Istoricheskii ocherk rasprostraneniia $i$ vosstanovleniia khristianstva sredi osetin). Preosviashchennyi Iosif, episkop Vladikavkazskii (1821-1890). Istoriko-biograficheskii ocherk zhizni $i$ deiatel'nosti "apostola Osetii' $i$ pervogo arkhipastyria Vladikavkazskoi eparkhii (Sostavil sviashchennik Ioann Popov) [Russian missions on the outskirts. Historical and ethnographic sketch. (Historical sketch of the spread and restoration of Christianity among the Ossetians). Joseph, Bishop of Vladikavkaz (1821-1890). Historical and biographical sketch of the life and work of the "Apostle of Ossetia" and the first archpastor of the Vladikavkaz diocese (compiled by priest Ioann Popov)], edited by A.A. Gorobets. Vladikavkaz: Olimp.

Kanukova, Z.V. and E.V. Fedosova. 2011. Etnokul 'turnoe prostranstvo Severnoi Osetii [Ethnocultural space of North Ossetia]. Vladikavkaz: IPO SOIGSI.

Kireev, F.S. 2015. Iz istorii khrama sviatoi ravnoapostol'noi Niny [From the history of the temple of St. Nina Equal to the Apostles]. Chyryston Ir (Pravoslavnaia Osetiia) 1 (4): 13-15.

Tsorieva, I.T. 2011. Puti ispovedimye... Iz istorii osnovaniia ravninnykh poselenii na Kavkaze $v$ kontse XVIII - XIXv. [From the history of the founding of lowland settlements in the Caucasus at the end of the 18th - 19th centuries.] Vladikavkaz: IPO SOIGSI. 